\title{
Da fragmentação à integralidade: construindo e (des)construindo a prática de saúde bucal no Programa de Saúde da Família (PSF) de Alagoinhas, BA
}

\author{
From fragmentation to integrality: constructing \\ and reconstructing the practice of buccal health \\ in the Alagoinhas (BA) Family Health Program
}

Adriano Maia dos Santos 1

Marluce Maria Araújo Assis 1

\footnotetext{
1 Núcleo de Pesquisa Integrada em Saúde Coletiva, Universidade Estadual de Feira de Santana.

Av. Universitária $\mathrm{s} / \mathrm{n}$ Módulo VI, 44031-460, Feira de Santana BA. adrianouefs@yahoo.com.br
}

Abstract A study about the practice of buccal health in the Alagoinhas - BA Family Health Program (2001-2004) with intent to analyze the arrangements that direct whole attention to buccal health: vinculum, reception, autonomy, responsibility and resolubility. The methodology is of qualitative nature in a historical-social perspective. The empirical material consists of interviews with health workers, managers and patients, the observing of the practice and documentary sources. The results show that the practice is organized through individual and collective actions built by a restrained demand. Attention is fragmented; there exists an excessive importance given to technique and specialization, whose axis is directed by the doctor-centered model with limited resolubility. Reception appears as a tense and conflicting relationship, however with a potentiality to build alternatives for change. Vinculum and autonomy cross link in the rescue of the worker-patient relationship and the encounter with their potentialities, which makes possible to level knowledge, narrow bonds and consolidate liking. To conclude, the practice of buccal health is full of conflicts and contradictions and is a potential tool for change in the work process, coexisting with the old (fragmentation) and the new (integrality) in an unfinished process still under construction.

Key words Practice, Buccal health, Family Health Program, Integrality, Health program
Resumo Estudo sobre a prática de saúde bucal no PSF de Alagoinhas - BA (2001-2004), com o objetivo de analisar os dispositivos que orientam a atenção integral à saúde bucal: vínculo, acolhimento, autonomia, responsabilização e resolubilidade. A metodologia é de natureza qualitativa, numa perspectiva histórico-social. Os materiais empíricos foram entrevistas com trabalhadores, gestores e usuários, observação da prática e fontes documentais. Os resultados revelam que a prática é organizada através de ações individuais e coletivas, construídas por uma demanda reprimida. $O$ atendimento é fragmentado com a valorização excessiva da técnica e da especialidade, cujo eixo é ordenado pelo modelo médico-centrado, com resolubilidade limitada. O acolhimento é manifestado através de uma relação tensa e conflitante, porém com potencialidade para construir alternativas de mudança. Vínculo e autonomia entrecruzam-se no resgate da relação trabalhadorusuário e no encontro de suas potencialidades, possibilitando horizontalizar saberes, estreitar laços e consolidar afetos. Enfim, a prática da saúde bucal é plena de conflitos e contradições e se constitui em potencial ferramenta de mudança nos processos de trabalho, convivendo com o velho (fragmentação) e o novo (integralidade), num processo inacabado, em construção.

Palavras-chave Prática, Saúde bucal, Programa Saúde da Família, Integralidade, Programas de saúde 


\section{Introdução}

O presente trabalho tem como objeto de análise a prática de saúde bucal no PSF em Alagoinhas (BA), de 2001 a 2004. Para tanto, buscamos compreender como são estabelecidas as relações a partir de dispositivos (ou agenciadores) de mudança, tomando como referências as produções de Campos1, 2, 3 e Merhy4, 5, 6, entre outros, que discutem os dispositivos de vínculo, acolhimento, coeficiente de autonomia, responsabilização e resolubilidade entre os sujeitos sociais envolvidos, direta ou indiretamente, na produção dos serviços de saúde.

Inspirados em Baremblitt7, compreendemos o dispositivo como sendo o que se contrapõe às estruturas funcionais e ao poder hegemônico. Portanto, está a serviço da mudança, da transformação, da construção e da produção do novo. O dispositivo, também chamado de agenciamento, é dinâmico, e, por isso, opera sem fronteiras, traz consigo a revolução, não cabe em parâmetros estabelecidos, cria novas possibilidades.

Portanto, a prática de saúde bucal integral teria que ser composta de um conjunto de agenciadores de mudança. Traçando uma analogia com a física, poderíamos conceber a integralidade no campo da saúde como um feixe de luz forma de energia que se propaga pelos espaços que, ao atravessar um prisma, se decompõe em diferentes cores. Cada cor - chamaremos de dispositivo - separada apresenta diferentes graus de força; ao se reagrupar às outras, restaura-se o feixe original, ou seja, recupera-se a potencialidade de iluminar - de criar novas perspectivas.

Nesse sentido, também como um feixe luminoso, a integralidade sofreria os mesmos fenômenos físicos - reflexão, refração ou absorção - ao incidir sobre diferentes instituições, organizações ou estabelecimentos, em espaços pouco permeáveis, que têm o processo de trabalho impregnado de instrumentos e conhecimentos estruturados. A princípio, os agenciadores sofreriam uma reflexão - voltariam para o ponto de origem - ao tentar transpor um obstáculo. Num segundo momento, rompendo-se alguns entraves, atravessariam o espaço, ainda que sofressem algum coeficiente de refração desvios de propostas. Num momento mais avançado, os dispositivos da integralidade romperiam as barreiras, construiriam novas formas de fazer/agir na prática cotidiana e seriam, portanto, disseminados e absorvidos pelos diversos sujeitos.

\section{Integralidade e tecnologias relacionais}

O debate em torno da integralidade converge também para um modelo de saúde concebido a partir de tecnologias relacionais do tipo acolhimento, que pode ser apreendido como ações comunicacionais, atos de receber e ouvir a população que procura os serviços de saúde, dando respostas adequadas a cada demanda, em todo o percurso da busca (recepção, clínica, encaminhamento externo, retorno, remarcação e alta).

O vínculo estreita-se com o acolhimento, ampliando os laços relacionais, desenvolvendo afetos e potencializando o processo terapêutico entre os usuários, os trabalhadores de saúde e os gestores do sistema. Seguindo esta lógica, a unidade de saúde passaria a organizar sua demanda, de acordo com as necessidades e prioridades - e não somente atrelada à ordem de chegada -, evitando-se, na medida do possível, filas desnecessárias e perda de tempo ${ }^{1}$.

Nessa direção, Campos ${ }^{3}$ argumenta que os serviços de saúde que pretendam de fato se responsabilizar pelos problemas da saúde precisam ter, por base, a ampliação do que ele denomina "coeficiente de autonomia" dos sujeitosusuários. A prática em saúde introduz os aspectos singulares do indivíduo, da família e da comunidade na condução terapêutica, através do compartilhamento de saberes entre trabalhador e usuário, como forma de garantir resultados mais eficientes no processo de cura e/ou no controle das morbi-mortalidades.

A responsabilização diante dos desafios do processo saúde/doença é a soma dos demais agenciadores, é a incorporação ao ato terapêutico da valorização do outro, a preocupação com o cuidado e o respeito com a visão de mundo de cada um; é, portanto, ser cúmplice das estratégias de promoção, prevenção, cura e reabilitação dos usuários.

Todos os dispositivos citados confluem para uma resposta adequada, uma solução para os problemas, ou seja, para a resolubilidade das demandas sentidas e apresentadas. Todos eles, contudo, compõem um dispositivo maior, um feixe de luz: a integralidade.

Por todos esses argumentos, seria equivocado esperar um conceito unívoco para integralidade, posto que perderíamos a sua totalidade e incorreríamos na possibilidade de restringir alguns de seus sentidos ainda inacabados, potenciais vetores de transformação das práticas no Sistema Único de Saúde (SUS) 8 . 
Diante dessa possibilidade de transformação, Merhy ${ }^{5}$ discute as ferramentas tecnológicas apropriadas para fazer um confronto com as sólidas instituições de saúde, apostando nas tecnologias leves - tecnologia de relações -, na ampliação das possibilidades terapêuticas e no redirecionamento do modelo de saúde comprometido com a defesa da vida.

Por outro lado, baseados em Campos ${ }^{1}$, Cecílio ${ }^{9}$ e Merhy ${ }^{5}$, defendemos a legitimidade dos conhecimentos estruturados (tecnologia levedura) e das máquinas, aparelhos e tantos outros (tecnologia dura), como fundamentais e/ou complementares na conquista da integralidade e humanização, em todo o percurso realizado pelos usuários na busca pela saúde.

\section{Metodologia do estudo}

Trata-se de uma pesquisa de abordagem qualitativa, numa perspectiva histórico-social, cujo recorte espacial foram três Unidades de Saúde da Família (USF) em que atuavam as Equipes de Saúde Bucal da Secretaria Municipal de Saúde de Alagoinhas - BA.

As técnicas de coleta de dados foram a entrevista semi-estruturada, a observação sistemática da prática e as fontes documentais. Os sujeitos do estudo foram 22 pessoas, que atuaram no período de 2001-2004, distribuídas entre quatro grupos de representação: grupo I (cirurgiões-dentistas e auxiliares de consultório dentário - ACD - 06); grupo II (outros trabalhadores de saúde - 06); grupo III (usuários do sistema - 05) e grupo IV (informantes-chave: prefeito, secretário de saúde, coordenador de saúde bucal, coordenador do Programa Saúde da Família - PSF - 05).

As entrevistas dos três primeiros grupos e as observações da prática foram orientadas por um roteiro, no qual constavam informações acerca do participante do estudo e dos dispositivos de análise: acolhimento, vínculo, responsabilização, coeficiente de autonomia, resolubilidade e relações estabelecidas entre os diferentes sujeitos que atuam, se responsabilizam ou se articulam com a prática de saúde bucal no PSF de Alagoinhas. As entrevistas com os informantes-chave foram livres, sem roteiro. A coleta de dados aconteceu no primeiro semestre de 2004.

$\mathrm{O}$ projeto de pesquisa foi submetido ao Comitê de Ética em Pesquisa (CEP), da Universidade Estadual de Feira de Santana, que avaliou a pertinência do mesmo, os objetivos da pes- quisa e os riscos e/ou benefícios a que estariam submetidos os participantes da investigação, de acordo com a Resolução 196, do Conselho Nacional de Saúde ${ }^{10}$.

A análise dos dados foi orientada pela hermenêutica-dialética segundo Minayo ${ }^{11}$, buscando-se, na especificidade de um contexto histórico-social, explicar e interpretar conflitos, relações e práticas sentidas, percebidas e experimentadas no cotidiano da atividade da saúde bucal. Em suma, pretendemos estabelecer o confronto entre os diferentes grupos pesquisados, através das convergências, divergências, diferenças e complementaridades, a fim de construirmos/reconstruirmos as categorias empíricas do estudo, articulando-as com o referencial teórico orientador, à procura de relações dialéticas entre elas. A síntese dos resultados das análises é apresentada seguir.

\section{Prática da Equipe de Saúde Bucal no PSF: ações individuais e coletivas com resolubilidade limitada}

A organização das atividades em saúde bucal revela que cada cirurgião-dentista organiza o processo de trabalho de tal forma que seis turnos sejam destinados ao atendimento em consultório (atividades curativas) e os outros quatro turnos utilizados em atividades preventivas nas escolas do município, para crianças na faixa etária de 6 a 14 anos (palestras, controle de placa, escovação supervisionada e aplicação tópica de flúor) ${ }^{12}$.

Nesse sentido, a prática de atenção à saúde bucal da realidade pesquisada traduz um viés característico das atividades preventivas na odontologia: o foco está centrado na atenção a escolares, na faixa etária de 6 a 14 anos, que estudam em escolas públicas, por meio de técnicas de escovação, aplicação de flúor e acompanhamento clínico13. Compreendemos que a prática, nesta perspectiva, fragmenta e reduz o campo do cuidado em saúde bucal, pois concentra as ações em uma faixa etária específica. Contudo, é no esteio dessa lógica de atenção que as ações preventivas vão se configurando no cotidiano das equipes de saúde bucal, de forma acrítica e limitada, na solução de problemas inerentes a este campo.

Constatamos que as ações fora do consultório são realizadas em quatro turnos semanais e devem contemplar as práticas coletivas: visitas domiciliares, planejamento, reuniões em equi- 
pe, capacitações, entre outras atividades. No entanto, devido à histórica exclusão por serviços clínicos e uma grande demanda reprimida, as Diretrizes da Política Nacional de Saúde Bucal sugerem que de 75 a $85 \%$ das horas trabalhadas pelo cirurgião-dentista no PSF sejam utilizadas na assistência curativa ${ }^{14}$.

Neste processo de organização das práticas de saúde bucal, a atenção individual também se apresenta com limites a serem superados. Sintetizadas as observações realizadas em três equipes, durante a coleta de dados, percebemos que: o atendimento individual é conduzido de maneira pontual; algumas vezes rápido, centrado na queixa do usuário; limitado pelo equipamento ou insumo disponível no momento e pelo número de vagas; sem garantia de retorno, restrito a um procedimento por indivíduo. Percebe-se também a falta de planejamento, concentrando a ação na figura do dentista, com falhas na biossegurança e na própria técnica utilizada para a realização da intervenção clínica. Dados semelhantes foram encontrados no município de Feira de Santana15.

As observações trazem à tona a discussão sobre o processo de trabalho do cirurgião-dentista, aqui especificamente a clínica desenvolvida na sua prática dentro do PSF. Para Campos ${ }^{1}$, poderíamos falar na existência de três clínicas, todas com particularidades importantes, que se comunicam e se interpenetram: clínica oficial, clínica degradada e clínica ampliada.

A primeira seria a tradicional clínica cartesiana, espaço no qual a prática desconhece a pessoa enferma e personifica a enfermidade, alienando-se nos seus objetos fetichizados exames, remédios, atos, protocolos, programas. A saúde é entendida como mercadoria 16 .

A segunda consiste numa clínica marcada por interesses de qualquer natureza - econômica, política, ideológica -, mas que, nesse caso, transfigura-se numa práxis distante das necessidades de saúde. Os diferentes interesses sobrepõem-se à promoção, prevenção, cura ou reabilitação dos usuários, impingindo a estes uma lógica de submissão.

A antítese seria a clínica ampliada, centrada no sujeito concreto - não somente na sua enfermidade -, a fim de resgatar a integralidade humana, o espaço de relações e de responsabilização na ação de cuidar das pessoas. Este é um movimento voltado para a ampliação do ato terapêutico, que valoriza as singularidades. Nesse caminhar, a clínica ampliada não polariza o conceito de saúde e doença como coisas que se ex- cluem, ao contrário, leva em conta a dialética desses conceitos, pois os compreende como imbricados num mesmo corpo, numa mesma sociedade, simultaneamente.

No cenário pesquisado, a clínica apresentase com limites em sua conduta terapêutica e de organização, necessitando reformulações que permitam a sua ampliação.

Não podemos negar, também, que a realidade em foco não foge da característica que marca a maioria dos municípios brasileiros e, principalmente, os nordestinos - a desigualdade social. É nesse panorama, portanto, que os aspectos econômicos, sociais, demográficos, culturais e epidemiológicos interferem no processo saúde-doença, constituindo um quadro complexo e heterogêneo que termina determinando o padrão de qualidade de vida das pessoas. E tudo isso produz um tipo de demanda demanda reprimida - que se materializa para as pessoas quando, mesmo tendo algum tipo de acesso aos serviços de saúde, têm sua resolubilidade limitada.

Portanto, a rede básica (incluindo as USF) precisa estar inserida num sistema funcional e resolutivo, com redes hierarquizadas de serviços, para se constituir em porta de entrada do sistema de saúde. Em síntese: trabalhar com um aparato científico-tecnológico capaz de resolver cerca de $80 \%$ dos problemas de saúde da população ${ }^{1}$.

De fato, a maioria das necessidades de saúde bucal poderia ser resolvida nas USF, se o requisito fosse a capacidade técnica dos profissionais. Na realidade, a forma como se organizam as práticas em saúde bucal nos conduzem a uma discussão polêmica - fazer ou não o "tratamento completado", ou seja, concluir todas as necessidades que cada usuário apresenta, pelo menos em relação aos procedimentos básicos, ou resolver apenas os problemas demandados em cada consulta.

O "tratamento não completado" gera, de um lado, uma maior rotatividade de usuários que utilizam os serviços, mas, por sua vez, cria um círculo vicioso, no qual a baixa resolubilidade acaba por gerar a permanência dos usuários por muito tempo no serviço, sem a garantia de que concluirão o tratamento ou conseguirão resolver os seus problemas.

Com freqüência, dado o caráter infeccioso das principais doenças bucais e em função da demora no atendimento, muitas unidades dentárias, que poderiam receber um tratamento conservador se cuidadas a tempo, acabam sen- 
do mutiladas. Outras vezes, quando o usuário consegue uma nova vaga, o que foi reparado hoje volta a ficar comprometido novamente, havendo a necessidade de outra intervenção.

A prática clínica defronta-se, ainda, com uma restrição nos serviços de saúde bucal, a assistência de média e alta complexidade. As Diretrizes da Política Nacional de Saúde Bucal14 reconhecem que a atenção em saúde bucal, nesses dois níveis, tem sido muito pequena, comprometendo a integralidade e a resolubilidade das ações. Ressalta-se, no entanto, que, só a partir de 2004, instituiu-se pela Portaria no 1571/ GM, em 29 de julho de 200417, uma política nacional de financiamento para a atenção de média complexidade em saúde bucal.

\section{Acolhimento: uma relação tensa, conflitante e potencial}

Acreditamos que a limitação na resolubilidade das práticas em saúde bucal faz parte da histórica dependência das ferramentas de trabalho (cadeira, instrumentais clínicos, entre outros), necessárias ao desenvolvimento das atividades curativas, mas não suficientes para atender às diferentes demandas de saúde. Nesse aspecto, podemos nos referir à saúde bucal como dependente das tecnologias duras e leve-duras, já que para a condução das ações na prática cotidiana ela requer a necessidade quase orgânica de um aparato instrumental - tecnologias duras - sustentado por conhecimentos bem estruturados (fisiologia, anatomia, patologia, epidemiologia, entre outros) - tecnologias leve-duras ${ }^{5}$.

Entendemos que o acolhimento acontece nos microespaços das relações individuais e coletivas, seja na recepção, na clínica, no tipo de acesso, nas palestras e reuniões desenvolvidas, no tipo de oferta de serviço, entre outras formas relacionais e comunicacionais existentes entre trabalhadores de saúde e usuários.

As observações realizadas nas USF demonstram que a recepção funciona segundo critérios administrativos, como meio para barrar ou limitar a demanda por serviços. Nesse sentido, a definição de clientela pode conflitar com o princípio da universalidade, pois o acesso passa a ser modulado pela ordem de chegada, cartazes informativos sobre o número de vagas, dias específicos para determinado grupo ou procedimento clínico, presença de determinado trabalhador na unidade, estado clínico geral do usuário, triagem ou seleção prévia de alguns ca- sos, entre outras formas de regular o acesso ao serviço.

Dois entrevistados (cirurgião-dentista e ACD) esboçaram uma postura mais relacional na recepção. O primeiro admite seu caráter humanizado e a preocupação em acolher, ainda que parcialmente, aquele que procura uma informação na unidade; da mesma forma, o ACD mostra-se envolvido com os aspectos subjetivos dos usuários que se dirigem à recepção, priorizando algumas necessidades, como as urgências e os atendimentos a idosos e gestantes.

Percebemos a potencialidade da comunicação quando, mesmo na ausência de vagas, os trabalhadores de saúde comprometem-se a tentar ajudar, de alguma maneira, o usuário, a partir da utilização do núcleo leve do seu saber - a relação. Na pesquisa, uma das dentistas não restringe suas ações cuidadoras a uma área adscrita, nem impõe ao usuário regras de normatização prescritas no receituário do PSF; ao contrário, a trabalhadora concentra seus esforços no ser que sofre, que apresenta uma necessidade que deve ser acolhida, independentemente de onde resida.

A linha de tensão se desvela com grau máximo no momento da marcação de consultas. Todas as equipes de saúde bucal no município utilizam uma forma de marcação, e cada uma delas já experimentou diversas alternativas no intuito de conceber um serviço mais próximo da universalidade e da equidade na atenção.

As entrevistas convergiram para o sistema de marcação, seja baseado na demanda espontânea e/ou centrado na doença. Demonstraram, também, o nível de desumanização na relação usuário-recepção, evidenciado na procura por consultas, uma situação em que não há garantia de vagas para todos. A limitação no número de consultas impõe uma disputa injusta entre os usuários, que passam a chegar cada vez mais cedo, de modo a garantir o acesso. Configura-se, assim, como um serviço excludente, conflituoso e tenso, caracterizando-se quase como uma seleção natural, na qual só os mais fortes conseguem sobressair. As observações comprovam que a grande maioria dos que ficam na fila é composta de adolescentes e adultos jovens, ao passo que as pessoas que trabalham, os idosos e as donas de casa acabam por ter dificuldade nesse tipo de organização.

As observações da prática também demonstraram não haver um processo acolhedor, no máximo constatamos formas diferenciadas de receber. A crítica assinalada pauta-se pelos rela- 
tos de experiências, materializados por Campos $^{1}$ e Franco et al.18, que se referem mais ao acolhimento na porta de entrada do que ao ato de receber de modo adequado. Impõe-se a necessidade de uma equipe que concretize tecnicamente o dispositivo; este, portanto, não pode se restringir ao porteiro, à agente administrativa ou ao ACD, ainda que eles estabeleçam interfaces no processo de cuidar.

No caso específico das práticas do cirurgiãodentista, as observações explicitaram várias arestas impregnadas de um fazer automatizado e ambíguo. Em alguns momentos, as tecnologias duras estiveram disponíveis à intervenção clínica. No entanto, o dentista realizou procedimentos rápidos, escolhendo sempre o mais simples de ser executado. Negligenciou as normas de biossegurança e rompeu com critérios clínicos estruturados, comprometendo a qualidade do procedimento produzido. Apesar disso, cada usuário que entrava e saía do consultório demonstrava satisfação quanto ao tratamento relacional proporcionado pelo profissional, ainda que alguns tenham se mostrado insatisfeitos com relação ao procedimento realizado.

Em outra observação da prática, o cenário é o inverso do anterior, pois o aparato tecnológico duro não é suficiente para a realização da maioria das intervenções clínicas (compressor quebrado e ausência de aparelho para esterilização). No entanto, o dentista, de forma criativa, executa procedimentos clínicos possíveis, mesmo sem estar obrigado a realizá-los, em razão das limitações impostas. O uso do arsenal leve é o grande diferencial, o profissional dá uma aula de como receber, ouvir e se responsabilizar pelo sofrimento do outro. Simultaneamente, ainda com resolubilidade limitada, procura, com as ferramentas disponíveis, contornar as dificuldades e desenvolver um processo de cuidado, centrado no usuário.

Temos ainda outros dados da pesquisa, apresentados de forma bastante contraditória. O profissional tem o melhor aparato tecnológico-estruturado disponível, entretanto resolve os problemas demandados de forma pontual e estabelece uma relação conflituosa com os usuários. Assim, tecnicamente produz serviços com primazia, ao mesmo tempo em que centraliza a conduta terapêutica, restringindo o acolhimento.

\section{O estabelecimento do vínculo na construção do coeficiente de autonomia}

Acioli19 e Campos² traduzem vínculo como o meio para realização de uma prática clínica de qualidade e integral, partindo da aproximação afetiva entre os sujeitos que cuidam e os sujeitos que são cuidados, e do reconhecimento legítimo do saber biomédico, porém agregado ao saber difundido, e também legítimo, dos ritos e práticas populares.

O material coletado durante as observações destaca-se pelo atendimento humanizado e a tolerância quanto aos desencontros de interesses entre trabalhadores e usuários. Em todas as USF visitadas, os usuários referiam os seus problemas ou os tratamentos que desejavam. Essa evidência também foi percebida em um centro de saúde de Ribeirão Preto - SP20.

Uma peculiaridade marcante, quando discutimos vínculo em relação à equipe de saúde bucal, é a forma como esta foi agregada às equipes de PSF no município. Por conta da proporção de uma equipe de saúde bucal para cada duas equipes de saúde da família, a diretriz do vínculo, mesmo a institucionalizada para as equipes do PSF, foi fragmentada para os dentistas/ACDs.

Nesse sentido, tornou-se um desafio maior para as equipes de saúde bucal, pois o número de pessoas vinculadas é o dobro em relação ao dos outros profissionais. As demandas individuais curativas em saúde bucal (restaurações, exodontias, raspagens) são resolvidas apenas pelos dentistas, ao contrário de outras demandas, compartilhadas por diferentes profissionais. Além disso, tornou-se também uma dificuldade para os usuários compreenderem que, dentro da equipe de PSF, um dos membros tem que dividir seus turnos de trabalho entre duas comunidades diferentes, restringindo o acesso das pessoas a turnos específicos, mesmo quando o dentista está na unidade.

Por outro lado, os desafios impostos pela estrutura organizacional congregam a necessidade do vínculo como agenciador das relações fragmentadas durante o processo de trabalho da equipe de saúde bucal. Nesta perspectiva, também percebemos que o PSF possibilita o entrelaçamento das relações e dos afetos entre os trabalhadores de saúde e a comunidade, ao fazer com que a prática ultrapasse os limites da USF.

Pela trajetória das falas dos diferentes trabalhadores de saúde, pudemos perceber tentativas 
de utilização de táticas diversas, com o intuito de dar conta da complexa luta para alterar as concepções tradicionais e incorporar novas alternativas na forma de fazer/agir em saúde. Para os sujeitos em questão, transparece a necessidade de ir além do que está posto, ser irreverente e, aliado a isso, aglutinar as pessoas para que se tornem cúmplices de um projeto coletivo. Mais do que isso, trata-se do propósito de resgate da relação trabalhador-usuário, relatada por alguns dos entrevistados, a fim de horizontalizar saberes, estreitar laços, consolidar afetos, estabelecer vínculo.

O coeficiente de autonomia é um expoente do grau de confiança, apego, identificação e sentimento de pertencimento, alcançados através do aprender/ensinar a maneira de se viver a vida, a saúde ou a doença. Vínculo e autonomia entrecruzam-se, constroem-se e agenciam-se, numa relação de nutrição placentária, que se processa a partir da sua presença nos interstícios das práticas sociais, no "ventre" da saúde e, portanto, no cerne da saúde bucal.

\section{A rede de relações dos diferentes sujeitos que protagonizam a prática de saúde bucal}

Os trabalhadores de saúde estabelecem interfaces entre si e com os usuários em espaços distintos e inusitados (USF, domicílios, escolas, ruas, igrejas, entre outros), muitas vezes além do território de adscrição, configurando-se, portanto, num complexo mosaico no qual acolhimento e vínculo podem (ou não) estar intermediando os encontros.

Os depoimentos coincidiram com as observações, revelando o quão distantes os entrevistados estavam de práticas interdisciplinares. Os trabalhadores têm uma concepção compartimentalizada do conhecimento de cada área, o que serve de justificação para a fragmentação do corpo; este, por sua vez, deve ser mediado por profissionais distintos, cada um com o seu papel definido. Assim sendo, ainda que compartilhem o mesmo espaço de trabalho, a prática permanece centrada no núcleo de conhecimento de cada trabalhador, ocasionando um desencontro dos saberes.

A rede de relações apresentada nas falas traz a reprodução das práticas em saúde, denunciando as assimetrias entre os diferentes sujeitos. Nesse sentido, os trabalhadores das diversas áreas cristalizam, através da divisão técnica do trabalho, um afastamento daquilo que julgam não ser de sua competência. Portanto, aprisionam o campo do cuidado, predominantemente inter-relacional, em uma atividade marcada pelo individualismo e o fracionamento dos atos terapêuticos.

Encontramos, em algumas falas, o trabalho em saúde recuperando a essência do ato de cuidar. Nesse âmbito, percebemos o deslocamento do eixo - recortado e reduzido - corporativocentrado, para o eixo - plural e complexo usuário-centrado ${ }^{21}$. O gradiente relacional que caracteriza a convivência entre as diversas áreas de saúde contribui para a resolução dos problemas dos usuários, pois implica a responsabilização dos diferentes trabalhadores e a conformação criativa da defesa da vida.

Porém, muitos depoimentos dão conta da dificuldade de reunir a comunidade em torno de discussões. Talvez a histórica exclusão das pessoas das arenas de decisão tenha impossibilitado a tomada de consciência em relação à importância de sua participação; talvez a forma como são organizadas as reuniões e as abordagens não consiga conquistar a atenção e o interesse da comunidade.

Concluímos, entretanto, que a pouca adesão também está associada ao formato acadêmico em que os encontros coletivos têm se desenvolvido, por meio de palestras verticalizadas e pouco problematizadoras. Constatamos, ainda, que muitas equipes organizam reuniões a partir das prioridades definidas pelo nível central da Secretaria Municipal de Saúde, como as conferências de saúde, os momentos de dispersão do treinamento introdutório para as equipes de saúde da família, ou para cumprir uma exigência do programa que determina a realização de reuniões na comunidade. Ou seja, as reuniões são propostas às pessoas de forma descontextualizada, nem sempre condizente com as reais necessidades dos territórios sociais, espaços de atuação das referidas equipes.

\section{Considerações finais}

Pensar a prática faz-nos refletir acerca de sua importância na estruturação do existir humano e de sua interdependência. Assim sendo, há a constituição de uma prática que determina modos e maneiras de agir dos sujeitos individuais e coletivos; e, no sentido inverso, uma interpenetração objetiva e/ou simbólica destes sujeitos no redimensionamento das ações humanas, ou se- 
ja, das práticas, que são, portanto, produtos das relações dialéticas.

Acreditamos que o debate em torno das práticas em saúde bucal demanda um modelo de atenção mais adequado, que possibilite agregar as diversas tecnologias (dura, leve-dura e leve) disponíveis da maneira mais adequada, sem reduzi-las nem tampouco ultrapassar as suas possibilidades. Até porque reduzir a prática em saúde bucal a determinismos pragmáticos ou funcionalistas não seria coerente com as propostas estudadas, muito menos excluir a legitimidade historicamente construída em seu arcabouço técnico-científico.

Nas análises delineadas na investigação em foco, intencionamos criar confrontos entre o posto e o proposto, procurando capturar os vetores que indicassem um caminho possível a ser trilhado ou descaminhos a serem desconstruídos.

Nessa seara de possibilidades, os caminhos foram sendo apontados no decorrer das discus- sões teórico-empíricas, que identificamos enquanto rupturas à hegemônica prática médicocentrada, individual e focalizada no trabalhador de saúde. A ênfase na equipe interdisciplinar, portanto, parece ser uma potencial ferramenta de mudança nos processos de trabalho, alicerçando a integralidade e seus dispositivos (acolhimento, vínculo, autonomia, resolubilidade, responsabilização) na confecção de práticas originais, de novos modelos.

O que ressaltamos aqui é que nem sempre é possível curar ou resolver uma necessidade apresentada, mas é sempre possível cuidar, escutar e contribuir para amenizar o sofrimento do outro. Até porque, quem adoece, adoece como um todo, ou seja, uma cárie, uma dor de dente, repercute na boca, no corpo, na alma, na vida. Junto com alguém que sofre, sofrem os que o amam, o sofrimento é então compartilhado, ainda que não dividido. Por isso, é patente a necessidade de trabalhadores sensíveis, com uma nova ética na saúde.

\section{Colaboradores}

Santos AM elaborou a pesquisa que deu origem ao artigo e participou da redação do mesmo. Assis MMA participou da redação do artigo. 


\section{Referências}

1. Campos GWS. Saúde paidéia. São Paulo: Hucitec; 2003.

2. Campos GWS. Um método para análise e co-gestão de coletivos. São Paulo: Hucitec; 2000.

3. Campos GWS. Subjetividade e administração de pessoal: considerações sobre modos de gerenciar trabalho em equipes de saúde. In: Merhy EE, Onocko R, organizadores. Agir em saúde: um desafio para o público. São Paulo: Hucitec; 1997. p. 229-66.

4. Merhy EE. Saúde: a cartografia do trabalho vivo. São Paulo: Hucitec; 2002.

5. Merhy EE. Em busca do tempo perdido: a micropolítica do trabalho vivo em saúde. In: Merhy EE, Onocko R, organizadores. Agir em saúde: um desafio para o público. São Paulo: Hucitec; 1997. p. 71-112.

6. Merhy EE. O SUS e um dos seus dilemas: mudar a gestão e a lógica do processo de trabalho em saúde (um ensaio sobre a micropolítica do trabalho vivo). In: Fleury S, organizadora. Saúde e democracia: a luta do Cebes. São Paulo: Lemos Editorial; 1997. p. 125 41.

7. Baremblitt G. Compêndio de análise institucional e outras correntes. 2a ed. Rio de Janeiro: Rosa dos Ventos 1994.

8. Mattos RA. Os sentidos da integralidade: algumas reflexões acerca de valores que merecem ser defendidos. In: Pinheiro R, Mattos RA, organizadores. Os sentidos da integralidade na atenção e no cuidado à saúde. Rio de Janeiro: IMS/Uerj, Abrasco; 2001. p. 3964.

9. Cecílio LCO. As necessidades de saúde como conceito estruturante na luta pela integralidade e eqüidade na atenção em saúde. In: Pinheiro R, Mattos RA, organizadores. Os sentidos da integralidade na atenção e no cuidado à saúde. Rio de Janeiro: IMS/Uerj, Abrasco; 2001. p. 113-26.

10. Brasil. Ministério da Saúde. Conselho Nacional de Saúde (CNS). Resolução no 196 de 10 de outubro de 1996. Dispõe sobre normas para pesquisa envolvendo seres humanos. Brasília; 2000

11. Minayo MCS. O desafio do conhecimento: pesquisa qualitativa em saúde. 6a ed. São Paulo: Hucitec; 1999.

12. Secretaria Municipal de Saúde. Relatório trimestral. Alagoinhas-BA: Coordenação de Saúde Bucal; 2001.
13. Zanetti CHG. Opinião: a inclusão da saúde bucal nos PACS/PSF e as novas possibilidades de avanço no SUS. 2002 [acessado $2002 \mathrm{dez}$ 9]. Disponível em: http://saudebucalcoletiva.unb.br

14. Brasil. Ministério da Saúde. Secretaria de Atenção à Saúde. Departamento de Atenção Básica. Coordenação Nacional de Saúde Bucal. Diretrizes da Política Nacional de Saúde Bucal. Brasília: MS; 2004.

15. Pereira DQ, Pereira JCM, Assis MMA. A prática odontológica em unidades básicas de saúde em Feira de Santana (BA) no processo de municipalização da saúde: individual, curativa, autônoma e tecnicista. Rev C S Col 2003; 8(2):599-609.

16. Figueiredo GO, Brito DTS, Botazzo C. Ideologia, fetiche e utopia na saúde: uma análise a partir da saúde bucal. Rev C S Col 2003; 8(3):753-63.

17. Brasil. Ministério da Saúde. Portaria no 1571/GM de 29 de julho de 2004. Estabelece critérios, normas e requisitos para a implantação e habilitação de Centros de Especialidades Odontológicas e Laboratórios Regionais de Próteses Dentárias. Brasília; 2004.

18. Franco TB, Bueno WS, Merhy EE. O acolhimento e os processos de trabalho em saúde: o caso de Betim (MG). In: Merhy EE, Magalhães HM, Bueno WS, Rimoly J, Franco TB, organizadores. O trabalho em saúde: olhando e experienciando o SUS no cotidiano. São Paulo: Hucitec; 2003. p. 37-54.

19. Acioli S. Os sentidos das práticas voltadas para a saúde e doença: maneiras de fazer de grupos da sociedade civil. In: Pinheiro R, Mattos RA, organizadores. Os sentidos da integralidade na atenção e no cuidado à saúde. Rio de Janeiro: IMS/Uerj, Abrasco; 2001. p. 157-66.

20. Matumoto S. O acolhimento: um estudo sobre seus componentes e sua produção em uma unidade da rede básica de serviços de saúde [dissertação]. Ribeirão Preto (SP): Escola de Enfermagem de Ribeirão Preto da Universidade de São Paulo; 1998.

21. Ceccim RB. Equipe de saúde: perspectivas entre-disciplinar na produção dos atos terapêuticos. In: Pinheiro R, Mattos RA, organizadores. Cuidado: as fronteiras da integralidade. São Paulo: Hucitec; 2004. p. 259-79.

Artigo apresentado em 25/04/2005

Aprovado em 18/08/2005

Versão final apresentada em 5/09/2005 